\title{
Analysis on the Artistic Quality of Seventy-two Mesas in Yimeng
}

\author{
Yan-qing $\mathrm{HOU}^{1, \mathrm{a},{ }^{*}}$ \\ ${ }^{1}$ Linyi University, Feixian, Shandong, China \\ alydxmfl@126.com
}

Keywords: Mesa in Yimeng, Aesthetic feature, Historical feature, Humanity character.

\begin{abstract}
Mesa in Yimeng has its unique features; it melds historic features, humanity character, folk customs, regional character, naturalness and so on, and then form its own unique artistic style. The article will analyze the inherent unique aesthetic sense of mesa in Yimeng from four aspects, that is, its exterior characteristics, spatial features, attribute features and the embodiment of artistic quality, and comb the artistic quality of mesa in Yimeng, then develop into detailed information, and provide new trains of thought for local tourism development.
\end{abstract}

\section{Introduction}

In the vast 9.6 million square kilometers of Chinese land, there is a place famous for its mesas: Yimeng. Yimeng and mesas, it's a usual combination. Mesas make Yimeng famous, meanwhile Yimeng makes the mesas civilized. Yimeng, is a history, a long, heavy history of scenery, of culture and of revolution. While mesa is a statue, a statue covered with beautiful scenery, touching legend and heroic stories. The battle of mesa Menglianggu that shocked the world happened in Mount Meng, the song "Mount Yimeng in Minor" makes the mount famous around the country.

It is true that the mesa is common among mountains at home and abroad, however, nowhere has such large amounts of mesas like Yimeng Mountain Area of Shandong province. The so-called "Seventy-two Mesas of Yimeng", is a compressed presentation, seventy-two is an approximate number. [1] Actually, the mesas in Yimeng Mountain Area is far more than seventy two. According to incomplete statistics, the number of mesas in the whole Yimeng Mountain Area is at least one thousand. It is probably because that the number seventy-two is highly favored by local people, like Confucius has seventy-two sages, Jinan has seventy-two springs, the Monkey King, Sun Wukong, has seventy-two changes, so the name "Seventy-two Mesas of Yimeng" come down through the years.

The Seventy-two Mesas of Yimeng have unique features. According to the survey of geologists, billions of years ago, the Yimeng mountain area was immersed in the ocean. During the process of Yanshan Movement in the late Jurassic Period of Mesozoic era and Himalayan movement in Cenozoic Tertiary period, the strata moved up and down along the faults, large number of fault block mountains looks like horsts were generated. After 150-million-years' weathering and erosion, these fault block mountains evolved into square-shaped mountains that are precipitous all round but flat on the top. Although being rarely seen in the world, such unique landforms can be seen everywhere in Yimeng Mountain Area. [2] The volume and the beautiful shapes of them are second to none in china, and have been hailed as "the wonder of the land, the pride of mountain". These mesas has dotted Yimeng Mountain Area with their special charm and 
magnificent appearance, and makes eight-hundred-mile Yimen much more charming and especially enchanting.

\section{The Classification of Mesas in Yimeng}

The names of mesas in Yimeng are strange, and can well reflect the personality of mesas. Generally speaking, it can be classified into the following categories:

Named after the historical character. Such as Mesa Menglainggu, Mesa Mother lv, Mesa of the king of the state of Ji, Mesa of the king of the state of Wu, Mesa Yanyinggu, Mesa Monk, Mesa Peddler and so forth.

Named after the feature on the mesa. The Mesa Songguding ("song" means pine tree) got its name because of the pine trees at the top of the mesa; Mesa Langu is named for the lingering fog; Mesa Firewood is named for large amounts of firewood on the mesa; Mesa Pond gets the name because that the top of the mountain is sunken, and the water of rainy season is stored here into a pond.

Named after the shape. For instance, the Mesa Awl, there is a platform at the top of the giant mountain, on the platform it's a giant erect rock, which looks like an awl into the sky; Transparent Mesa get the name because there is a round cave in the cliff, and the transparent sky can be seen when looking from one side of the cave; Mesa of reclining Buddha, several mesas connected with each other at intervals, looks like a Buddha lying on his back; Mesa crooked- head is named for the exterior feature that the top of the mountain is tilted to one side; Mesa Dragon lokks like a giant drahgon, and lying at the top of mountain; Mesa Stone-man, the stone man stands at the mountains all throughout the year, no matter whether it is summer or winter; Mesa of mother and child looks like that mother and child lean on each other; Mesa Column lokks exactly like a column; Mesa Niutougu looks like the head of cattle; Mesa Eagle- beak looks like that the eagle is pecking into the sky......

Named after the way of combination. For instance, the Triangle Mesa, the top oof the mesa extended into three sides, and formed into triangle; Mesa Liangu, like two great walls connected with each other; Double Mesa connected with each other side-by-side.

Named after the family name or the name of the village. Such as Mesa Kongjiagu, Mesa Liujiagu, Mesa Jiangjiagu, Mesa Fanjiagu, Mesa Zhujaigu, Mesa Niujjiagu, Mesa Xujaigu, Mesa Sunjiagu;

Named after the myths and legends. For instance, Mesa Daigu, it is said that Mountain Tai can be seen at the top of it, so it got the name Wangdaigu. then the name evolved into abbreviation, Daigu. Mesa Baodugu (holding calf in arm) is named for the legend that ancient people hold the calf in arm when climb mountains.

Named after the farming. For example, Mesa Cattle-grazing, Mesa Pigsty, Mesa scissors, and so forth.

\section{The Aesthetic Features of Mesas in Yimeng}

\section{The Exterior Characteristics}

The mesa, also named square-shaped mountain, is the geographic phenomenon caused by the earth's crust movement and the fault. Large amounts of limestone and quarts sandstones are laying flat on the top of the mountain, seen from a distance, the mountains look like wearing a flat hat. The basic characteristics of it is flat top, steep cliff-the top of the mesa is usually flat, while the sides are very steep, and the slope under the cliff is changing from steep to gentle. The features of mesas in Yimeng lie in 
its shape, beauty, precipitousness, and overlap. The shape means the mesas resemble human person, animals or objects in shape, no matter in big or small size, they are born like this; the beauty means their connation, the stones look vividly, beautiful and special; the precipitousness means the mesas is very steep, the crevice and grooves makes them much bumpier. Overlap means the surface of the mesas are undulating, it have well-proportioned changes, and has the feeling of having suffered a lot [3].

\section{The Spatial Features}

The seventy-two mesas in Yimeng have various forms and charm. In big or small size, no matter magnificent, steep, or elegant, they look very gorgeous. Some mesas look like a giant mushroom emerged from the top of the mountain, some like a doctor's cap, some like stone mill squatting on the mountain top, some like ancient round chess pieces, and some like partial round peg. The Yimeng mountain area is dotted with mesas that have various forms and unique charm; such mesas also bring new flavors to the area, and initiate pleasing imaginations of people.

\section{The Attribute Features}

Naturalness, strangeness, humanity character, ornamental value, historic features and revolutionary features are the important attributes covered by mesas in Yimeng. Naturalness, including form, color, texture and quality, is the essential attribute of mesas in Yimeng, Strangeness means the typical difference between mesas in Yimeng and common mesas, and it is caused by the different combination ways of mesas in Yimeng, also is the origin of ornamental value and artistic quality. Humanity character points to the sociality of the objects reflected by the mesas in Yimeng, the humanity character of different mesas in Yimeng are different, the mesas reflect social images has much stronger humanity character. Ornamental value is the subjective reaction of aesthetic subject on the Naturalness, strangeness, historic features and revolutionary features of mesas in Yimeng, is results from such comprehensive factors as infection of beauty of mesas in Yimeng, aesthetic ability of aesthetic subject and aesthetic relation between the subject and object, for instance, in the battle of Mesa Menglianggu, "The Six Sisters" that support the army and the front-line emerged. Meanwhile, three are many great men and women grew up from mesas in Yimeng, for instance, the great hero, Lin Maocheng, kill the enemy bravely, and get remarkable battle achievements, and is dubbed the title of "super military hero in the East China", and there heroes like Huang Jiguang, the revolutionary martyr, Li Yaode. These heros grow up from the mesas in Yimeng, and add splendid poem to the mesas in Yimeng. Looks like steel forts, the lofty mesas in Yimeng is standing among the Mountain Meng and Yishui River, and is the monument given by god to honor the glory and dedications of the revolutionary martyr and people of revolutionary area [4].

\section{The Embodiment of Artistic Quality}

Mesas in Yimeng have proved us rich aesthetic experiences, combined with the aesthetic theory, we get primary understanding of basic features of mesas in Yimeng, and it is concluded as follows:

\section{Mesas in Yimeng has the Structure of Art}

The hierarchy of mesas in Yimeng like image, artistic conception, charm and theme are direct carriers, and are important artistic elements of ideology; the shape, color, texture and quality ate indirect carriers, are material means of creating images; the division and 
unity of two kinds of carrier lies in social practice. Therefore, the mesas in Yimeng have structure of art.

\section{Mesas in Yimeng has Aesthetic Function of Art}

In the forms of beauty, mesas in Yimeng have two forms: natural beauty and reflecting beauty. Natural beauty is the essential beauty of Yimeng, the shape, color, texture and quality of mesas in Yimeng can be singled out as aesthetic object and become formal beauty. Mesas in Yimeng includes all kinds of forms of beauty.

From the mature and features of beauty, the mature of mesas in Yimeng is as same as that of usual beauty. The creativity of the "image" of beauty of mesas in Yimeng, is embodied in the rational discovery we get from the process of appreciating humanity, historic features, folk customs, appreciation value, visuality and extensity,

From the generation of beauty, three are similarities and differences between beauty of mesas in Yimeng and the usual beauty. They are both based on the social practices, transfer from the practical sense of form to aesthetic sense of form, from unconscious to conscious, from superficiality to profundity. The difference lies in that the beauty of mesas in Yimeng has learned from the aesthetic mode or experiences of painting and sculpture, and combined with historic features, folk customs, revolutionary feature and regional character, meanwhile it select modern aesthetic theory as guidance and aesthetic sensation of the newest art form.

The Mesas in Yimeng are Spatial Art, Visual Art, Natural Art, and Art to be Found

For the art of mesas in Yimeng, the "artistic figure" comes before "artistic image". The viewer appreciate the artistic figure, and combine with the historical feature, folk customs , cultural feature, and regional character, to feel the artistic conceptions. Shape, color, texture and quality are the doodles of "nature artist", human beings can do nothing on the creating method, what we can do is to follow behind the nature artist to select and filter the social and natural images provided by the human social practices, to a certain extent, such creation is at higher level.

\section{Summary}

Seventy-two mesas in Yimeng are all very famous, and colorful, almost every mesa has a beautiful legend. These different forms of mesas generate enormous legendary sense with the infusion of humanity history. The legends with long history have added profound cultural heritage to the culture of mesas in Yimeng. Like sheng, dan, jing, mo, chou in Beijing opera, these different forms of mesas are vivid and has artistic features, shows the harmonious unity of the mankind and nature, of natural landscape and cultural landscape. In this magical land, mesas condense the spiritual influence of the local soil and waters, and influence the words and actions of local people indirectly, result in the honesty, generosity, simplicity and sincerity of people of Shandong. [5] Geographically speaking, both the Mountain Tai, that is known as the most revered one of China's five sacred mountains, and eight-hundred-mile Mountain Yimeng, which is rich in red spirit, are famous for their sincerity and massiness, and also represents the typical characters of people of Shandong. From the aspect of humanity history, Confucianism represented by Confucius constitutes the particular spirit of participating into society positively and building career. From this, the spirits of people of Shandong 
has inseparable relations with its cultural background and special geography; this is exactly the reason that different lands nurture different people.

\section{References}

[1] Li Ligang, Mesas in Yimeng [M] Beijing: China Publishing House, 2003.

[2] Editoral Board of Complete Sets of Collection and Appreciation of Chinese Art: Complete Sets of Collection and Appreciation of Chinese Art: Rare Stone [M] Changchun: Northern China Women \& Children Publishing House, 2007.

[3] Li Shengli, Introduction To Art [M]. Communication University of China Press, 2004.

[4] Humanity Datum Committee of Feixian Political Consultative Congress Edited: Collections of Feixian Humanity Datum [M] Jinan: Shandong Cartographic Publishing House, 2003. 